•研究报告・

\title{
生物多样性相关传统知识调查与评估：以澜沧与康 定两县域为例
}

刘冬梅 ${ }^{\mathbb{D} 1}$, 李果 ${ }^{1}$, 李俊生 ${ }^{1 *}$, 杨京彪 ${ }^{(12 *}$, 肖能文 ${ }^{1}$

1. 中国环境科学研究院生态研究所, 北京 100012; 2. 中央民族大学生命与环境科学学院, 北京 100081

摘要: 本研究依据《县域生物多样性相关传统知识调查与评估技术规定》, 调查评估了云南省澜沧县和四川省康定市两县域 生物多样性相关传统知识的分布数量与特征, 分析了传统知识保护与传承状况, 识别了主要受威胁因素和保护空缺, 旨在为 我国传统知识保护和民族地区实施传统知识获取与惠益分享制度提供科学依据, 推动《生物多样性公约》与《名古屋议定书》 等国际公约的履行。研究结果如下: 分别调查编目澜沧县、康定市的生物多样性相关传统知识145项、98项; 这些传统知识 具有明显的地区气候与自然环境特征、生产生活实践特征、传统文化特征和地区社会经济特征; 相关部门在传统知识保护管 理方面做出了积极努力，同时包括习惯法、传统节庆等传统文化和包括祭祀、神山、神林等宗教方式在内的地方社区行动在 传统知识保护与传承方面也发挥了重要作用; 生物多样性相关传统知识、创新和做法已被广泛应用于地方社区脱贫攻坚和产 业发展; 传统知识保护立法仍不健全、受到威胁、保护意识薄弱及承载传统知识的生物资源减少是制约传统知识保护传承的 主要因素。两县域生物多样性相关传统知识丰富, 并且地方社区有效参与了生物多样性相关传统知识的保护与可持续利用。 今后应建立传统知识获取与惠益分享国家制度; 加强宣传教育, 提升保护传承意识; 因地制宜开展传统知识保护; 推动传统 知识相关生物资源的保护与可持续利用。

关键词: 生物多样性相关传统知识; 调查; 评估; 惠益分享; 县域

刘冬梅, 李果, 李俊生, 杨京彪, 肖能文 (2021) 生物多样性相关传统知识调查与评估: 以澜沧与康定两县域为例. 生物多样性, 29, 184-192. doi: 10.17520/biods.2020492.

Liu DM, Li G, Li JS, Yang JB, Xiao NW (2021) Investigation and evaluation of traditional knowledge associated with biodiversity: A case study in Lancang and Kangding ethnic counties. Biodiversity Science, 29, 184-192. doi: 10.17520/biods.2020492.

\section{Investigation and evaluation of traditional knowledge associated with biodiversity: A case study in Lancang and Kangding ethnic counties}

\author{
Dongmei Liu ${ }^{(1)}$, Guo $\mathrm{Li}^{1}$, Junsheng $\mathrm{Li}^{\left({ }^{1 *}\right.}{ }^{*}$, Jingbiao Yang ${ }^{\left({ }^{*}\right.}$, Nengwen Xiao ${ }^{1}$ \\ 1 Institue of Ecology, Chinese Research Academy of Environmental Sciences, Beijing 100012 \\ 2 College of Life and Environmental Sciences, Minzu University of China, Beijing 100081
}

\begin{abstract}
Aims: Traditional knowledge (TK) associated with biodiversity is one of the important topics outline in the Convention on Biological Diversity and Nagoya Protocol. This study reports the characteristics, main threat factors and protection gaps of TK associated with biodiversity in Lancang County of Yunnan Province and Kangding City of Sichuan Province. The study will provide a scientific basis for promoting the protection of TK, the implementation of TK access and benefit-sharing (ABS) systems in ethnic minority areas, and the adoption of international conventions.

Methods: From 2016 to 2018, we investigated and evaluated TK associated with biodiversity in Lancang County and Kangding City, using the "Technical guidelines for investigation and assessment of TK associated with biological diversity at county level". We used the snowball sampling method to sample the target groups, determined the holders of TK, and then interviewed key people.
\end{abstract}

Results: In Lancang County, 145 examples of TK associated with biodiversity were recorded, and 98 examples were

收稿日期: 2020-12-31; 接受日期: 2021-02-18

基金项目: 生态环境部生物多样性调查与评估项目(2019HJ2096001006)

* 共同通讯作者 Co-authors for correspondence. E-mail: lijsh@craes.org.cn; yangjingbiao@muc.edu.cn 
recorded in Kangding City. These TK had obvious regional climate and natural environment characteristics, production and life practice characteristics, traditional cultural characteristics and socio-economic characteristics. Relevant government departments made positive efforts in the protection and management of TK, and local community actions, including traditional culture (customary law, rituals, etc.) and religious beliefs (sacrifice, sacred mountain, sacred forest, etc.) also played an important role in the protection and inheritance of TK. TK, innovation and practices associated with biodiversity were widely used in poverty alleviation and industrial development of local communities in Lancang County and Kangding City. The main threats to TK included the imperfect legislation of TK protection, extinction and endangerment, the low awareness of protections and the reduction of biological resources associated with TK.

Conclusion: There is rich TK associated with biodiversity in both examined counties, and local communities effectively participate in the protection and sustainable use of TK. In the future, the relevant departments should establish a national system for TK access and benefit sharing; strengthen publicity and education to enhance the awareness of protection and inheritance; protect TK according to local conditions; and promote the protection and sustainable utilization of biological resources associated with TK.

Key words: traditional knowledge associated with biodiversity; investigation; evaluation; benefit sharing; county level

《生物多样性公约》及《名古屋议定书》中的 生物多样性相关传统知识, 主要是指来自土著与地 方社区、体现其传统生活方式并与生物多样性的保 护和可持续利用相关的知识、创新和做法(Jeeva, 2006; 薛达元和郭泺, 2009; Leni, 2016)。生物多样 性相关传统知识具有潜在或已体现的重要经济价 值, 常被应用于现代工业和农业生产中(Pushpangadan et al, 2018)。许多常用药物、化妆品、保健品 等都基于传统知识而开发, 如抗㾏药青蒿素的发现 就是基于古代医书《时后备急方》(薛达元, 2019)。 传统知识对生物多样性保护和可持续利用的重要 作用也越来越受到重视(Antons, 2010; 成功等, 2012; Jasmine, 2016; 张渊媛, 2019)。然而, 生物多 样性和生态系统服务政府间科学政策平台(IPBES) 于2019年5月发布的生物多样性和生态系统服务全 球评估报告表明, 全球生物多样性相关的传统知识 仍在快速消失(IPBES, 2019), 亟需采取有效的保护 措施。

近年来, 我国学者在少数民族地区开展了一系 列生物多样性相关传统知识调查, 如王国萍等 (2019)对我国青海省土族聚居区的土族生物资源利 用相关的传统知识进行了系统调查与编目, 并借鉴 生物多样性测度方法, 创建了传统知识多样性指数 计算方法; 杨云卉等(2019)调查了西双版纳黄瓜 (Cucumis sativus var. xishuangbannanesis)农家品种 及其相关的传统知识, 建议开展西双版纳黄瓜农家 品种的原生境保护; 杨立新等(2019)调查了白马雪 山国家级自然保护区及其周边地区 3 个藏族村寨的 自然圣境与生物多样性分布状况及其生态服务功
能等，发现藏民社区长期的自然圣境知识、创新和 做法对生物多样性保护做出了重要贡献。但是这些 调查总体上比较零散, 缺乏全面性、系统性, 未使 用统一的方法进行调查、记录、整理、编目和评估。 由于未涉及行政单元, 对于当地政府采取保护规划 和行动措施也不便利。

本研究梳理了国际和国内有关生物多样性相 关传统知识保护的规定和要求, 选取云南省普洱市 澜沧拉祜族自治县(简称澜沧县)和四川省甘孜藏族 自治州的康定市为示范地, 调查并评估县域生物多 样性相关传统知识的分布数量、特征和保护传承状 况, 明确了主要威胁因素和保护空缺, 拟为地方政 府制定传统知识保护规划和采取切实措施提供科 学依据, 并为民族地区实施传统知识获取与惠益分 享制度提供参考。

\section{国内外对生物多样性相关传统知识保护的}

生物多样性相关传统知识的保护与可持续利 用是《生物多样性公约》(以下简称《公约》) 的重 要内容之一。2010年, 《公约》第十次缔约方大会 通过了《2011-2020生物多样性战略计划》及爱知 生物多样性目标(以下简称爱知目标)。爱知目标第 18项提出 “到2020年, 土著和地方社区的保护和可 持续利用遗传资源有关的传统知识、创新和做法及 其对于生物资源的习惯性利用, 根据国家立法和相 关国际义务得到了尊重, 并在土著和地方社区在各 国相关层次上的有效参与下, 充分地纳入和反映在 《公约》的执行工作中” (https://www.cbd.int/doc/stra tegic-plan/2011-2020/Aichi-Targets-EN.pdf)。2010年9 
月, 国务院批准实施的《中国生物多样性保护战略 与行动计划》(2011-2030年)提出“推动建立生物遗 传资源相关传统知识的获取与惠益共享制度, 公 平、公正地分享其产生的经济效益”的战略任务, 并 将“开展生物多样性相关传统知识的调查编目”和 “建立生物多样性相关传统知识保护、获取和惠益 分享的制度和机制”列为优先行动 (http://www.mee.gov.cn/gkml/hbb/bwj/201009/t20100 921_194841.htm)。

为落实《中国生物多样性保护战略与行动计 划》(2011-2030年), 2014年生物多样性保护国家委 员会审议通过的《生物多样性保护重大工程实施方 案(2015-2020年)》, 提出“以县域为单元, 开展全国 陆地生物多样性保护优先区的生物多样性相关传 统知识调查与评估”。为使调查与评估工作标准化、 统一化和规范化, 原环境保护部组织制定并于 2017 年发布了《县域生物多样性相关传统知识调查与评 估技术规定》( 以下简称 “技术规定”) (http://www.mee.gov.cn/gkml/hbb/bgg/201801/t20180 108_429275.htm; 刘冬梅等, 2018)。该规定的调查指 标包括类别、生物基源、持有者、数量、分布、传 统利用、知识产权、特有性、惠益分享、丧失或流 失、威胁因子等, 充分考虑了爱知目标18和我国生 物多样性相关传统知识保护、获取和惠益共享的需 求。根据薛达元和郭讶(2009)的分类方法及原环境 保护部于 2014年5月30日发布的《生物多样性相关 传统知识分类、调查与编目技术规定》 (http://www.mee.gov.cn/gkml/hbb/bgg/201406/t20140 606_276593.htm), 传统知识可分为5大类: (1)传统 选育农业遗传资源的相关知识; (2)传统医药相关知 识; (3)与生物资源可持续利用相关的传统技术及生 产生活方式; (4)生物多样性相关的传统文化; (5)传 统生物地理标志产品。

此外, 我国于 2011 年开始实施的《非物质文化 遗产法》和2017年开始实施的《中医药法》都对生 物多样性相关传统知识的保护和可持续利用产生 了重要影响。

\section{县域生物多样性相关传统知识的调查}

2016-2018年，依照技术规定在澜沧县和康定 市开展生物多样性相关传统知识的调查与评估。调
查采用滚雪球抽样法对目标群体进行抽样, 确定传 统知识持有方, 对关键人物进行访谈(刘冬梅等, 2018)。实地调查获得的数据将为评估各县域生物多 样性相关传统知识的基本特征、受威胁状况、保护 与传承状况提供基础。

依照《中国生物多样性保护战略与行动计划》 的优先行动 8 的要求, 重点调查了澜沧县、康定市少 数民族地区与生物遗传资源相关的传统知识、创新 和做法, 并建立了澜沧、康定县域传统知识数据库。 澜沧县域传统知识数据库收录了生物多样性相关 传统知识145项，包括传统选育农业遗传资源的相 关知识 60 项、传统医药相关知识 52 项、与生物资源 可持续利用相关的传统技术及生产生活方式13项、 与生物多样性相关的传统文化 11 项和传统生物地 理标志产品相关知识 9 项。康定县域传统知识数据 库收录了生物多样性相关传统知识98项, 包括传统 选育农业遗传资源的相关知识40项、传统医药相关 知识39项、与生物资源可持续利用相关的传统技术 及生产生活方式7项、生物多样性相关的传统文化5 项和传统生物地理标志产品相关知识7项。

澜沧县居民以拉祜族为主，创造积累了选育和 栽培大叶种茶树的有效方法, 保存了具有 1,300 多 年历史的景迈芒景万亩栽培型古茶园和邦崴千年 过渡型大茶王树。景迈芒景千年万亩古茶园是迄今 为止国内面积较大、种植历史较长、保存比较完整 的人工栽培型古茶园, 被称为“世界茶树博物馆”和 “茶叶种类活化石”。澜沧县布朗族将茶树视为神树, 传承了采茶、制茶、饮茶的做法。每年春茶发芽之 季, 布朗族举行盛大的“山康茶祖节”, 到茶山祭拜 茶魂, 祈求祝福, 是传承千年的布朗族文化。山康 茶祖节是布朗族朴素生态伦理观的体现, 在一定程 度上促进了古茶树的保护和大叶种茶资源的可持 续利用, 于2017年被列入 《云南省第四批非物质文 化遗产保护名录》。转山会是康定地区各民族一年 一度重大的民俗传统节日。康定转山会又称沐佛 节、敬山神, 其中包括了转山祭神, 是藏族神山圣 境文化的直观体现，表达了藏族对自然的敬畏和尊 重。2014年, 康定转山会被列入国家级非物质文化 遗产扩展项目名录, 编号 X-85。

对澜沧县和康定市现存生物多样性相关传统 知识进行系统编目, 部分代表性传统知识列于表 1 。 
表1 澜沧县和康定市部分重要传统知识列表

Table 1 List of important traditional knowledge (TK) in Lancang Couty and Kangding City

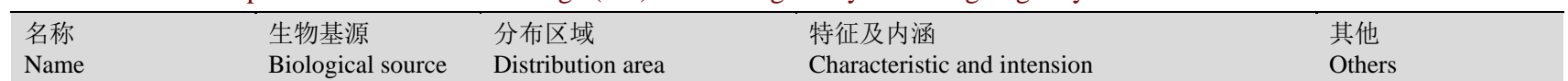

传统选育农业遗传资源的相关知识 Traditional knowledge of breeding agricultural genetic resources

$\begin{array}{lll}\text { ‘澜沧栘依 } & \text { 栘依 } & \text { 澜沧县特有 } \\ \text { Lancang Duoyi } & \text { Docynia delavayi } & \text { Endemic to Lancang } \\ & & \text { County }\end{array}$

澜沧古茶茶

Lancang ancient tea Camellia sinensis South of Yunnan Province
培育的传统品种——甜多依, 具有食用、药

用、酿酒用等多种用途, 并举办一年一度的栘

依节

Cultivated a traditional variety, "tianduoyi",

which is used for food, medicine, wine-making

and other purposes, and held an annual Duoyi

Festival

创造积累了栽培茶树和制作茶叶的传统知识, 成为当地各民族生计和生活中不可替代的一 部分

Created and accumulated the traditional

knowledge of tea cultivation and tea production,

which has become an irreplaceable part of the

livelihood and life of local ethnic groups

\begin{tabular}{|c|c|c|}
\hline ‘接骨糯’ & 水稻 & 中国南部地区 \\
\hline Jiegunuo & Oryza sativa & South of China \\
\hline ‘康定红皮萝卜’ & 夢卜 & 康定市特有 \\
\hline Kangding radish & $\begin{array}{l}\text { Broussonetia } \\
\text { papyrifera }\end{array}$ & Endemic to Kangding City \\
\hline ‘康定芫根’ & 芫根 & 康定市特有 \\
\hline Kangding swede & Brassica rapa & Endemic to Kangding City \\
\hline 康定雪茶 & 雪茶 & 青藏高原及周边高寒山地 \\
\hline Kangding snow tea & $\begin{array}{l}\text { Thamnolia } \\
\text { vermicularia }\end{array}$ & $\begin{array}{l}\text { Tibetan Plateau and its } \\
\text { surroundings }\end{array}$ \\
\hline
\end{tabular}

传统医药相关知识 Traditional medicinal and its related knowledge

\begin{tabular}{|c|c|c|}
\hline 白豆花 & 粗柄杜娟 & 拉祜族社区 \\
\hline Baidouhua & $\begin{array}{l}\text { Rhododendron } \\
\text { decorum }\end{array}$ & Lahu community \\
\hline 肾炎那此 & 肾茶 & 拉祜族社区 \\
\hline Shenyan naci & $\begin{array}{l}\text { Clerodendranthus } \\
\text { spicatus }\end{array}$ & Lahu community \\
\hline 虫草 & 冬虫夏草 & 藏族社区 \\
\hline Cordyceps & Cordyceps sinensis & Tibetan community \\
\hline 人参果 & 蕨麻 & 藏族社区 \\
\hline Renshenguo & Potentilla anserina & Tibetan community \\
\hline 藏族传统药浴疗法 & - & 藏族社区 \\
\hline $\begin{array}{l}\text { Tibetan medicine } \\
\text { bath therapy }\end{array}$ & & Tibetan community \\
\hline 拉祜族药䉼疗法 & - & 拉祜族社区 \\
\hline $\begin{array}{l}\text { Medicine porridge } \\
\text { therapy of Lahu } \\
\text { People }\end{array}$ & & Lahu community \\
\hline
\end{tabular}

培育的地方品种, 具有极高的食用、药用、饲 地方特产

用和文化价值

Cultivated a local rice variety with edible,

medicinal, feeding and cultural value

培育的适应当地高寒气候的地方萝卜品种,

具有食药两用功能

Cultivated a local radish variety adapted to the local alpine climate with dual functions of food and medicine

培育的优良芫青品种, 具有重要的食用、药用

和文化价值

Cultivated a good swede variety with important edible, medicinal and cultural value

康定市藏族社区传统使用的天然保健饮品

Traditional natural health drink for Tibetan

community in Kangding City

\section{拉祜族传统食花和食疗文化的典型}

The typical culture of flower eating and diet

therapy

传统治疗肾类疾病的草药知识

Traditional herbal medicine knowledge for

kidney diseases

藏族传统名贵天然保健品

Traditional valuable natural health

care products of Tibetan community

藏族传统食用的保健品, 当地称为人参果

Tibetan traditional health care products, locally known as the "fruit of life"

藏族传统医疗诊法之一, 主治风湿类关节炎

It is one of the traditional Tibetan medical methods, mainly for rheumatoid arthritis 传统食疗方法之一, 具有预防疾病、补充治 疗、调补养生等功效

It is one of the traditional dietotherapy methods, which has the functions of disease prevention, supplementary treatment, tonic and disease preservation

\section{与生物资源可持续利用相关传统技术 Traditional technologies of sustainable use of biological resources}

\begin{tabular}{|c|c|c|c|}
\hline 富邦腊肉 & 家猪 & 澜沧县特有 & 以地方品种 “滇南小耳猪”为原料的腊肉制作 \\
\hline Technique of making & Sus scrofa & Endemic to Lancang & 技艺 \\
\hline Fubang bacon & domesticus & County & $\begin{array}{l}\text { The technique of making bacon with local pig } \\
\text { variety-'Diannan xiaoerzhu' as raw material }\end{array}$ \\
\hline 拉祜族葫芦笙制作 & 葫芦 & 拉祜族社区 & 以葫芦作为共鸣箱的笙, 是拉祜族最具特色 \\
\hline 技艺 & Lagenaria & Lahu community & 的传统乐器 \\
\hline $\begin{array}{l}\text { Technique of making } \\
\text { gourd Sheng of Lahu } \\
\text { People }\end{array}$ & siceraria & & $\begin{array}{l}\text { The most distinctive traditional musical } \\
\text { instrument of Lahu People, with gourd as } \\
\text { resonance box }\end{array}$ \\
\hline
\end{tabular}

地理标志证明商标

Geographical

indication

certification

trademark

地理标志产品(普洱

茶)

Geographical

indication products

(Pu'er Tea)

地方特产

农产品地理标志

Geographical

indication of

agricultural products

农产品地理标志

Geographical

indication of agricultural products

地方特产

Local speciality

地方特产

Local speciality

地方特产

Local speciality

地方特产

Local speciality

地方特产

Local speciality

市级非遗项目

Municipal intangible cultural heritage

地方特产

Local speciality

地方特产

Local speciality

省级非遗项目

Provincial intangible cultural heritage 
表1 (续) Table 1 (continued)

\begin{tabular}{|c|c|c|c|c|}
\hline $\begin{array}{l}\text { 名称 } \\
\text { Name }\end{array}$ & $\begin{array}{l}\text { 生物基源 } \\
\text { Biological source }\end{array}$ & $\begin{array}{l}\text { 分布区域 } \\
\text { Distribution area }\end{array}$ & $\begin{array}{l}\text { 特征及内涵 } \\
\text { Characteristic and intension }\end{array}$ & $\begin{array}{l}\text { 其他 } \\
\text { Others }\end{array}$ \\
\hline $\begin{array}{l}\text { 传统手工造纸技艺 } \\
\text { Traditional } \\
\text { handmade } \\
\text { papermaking } \\
\text { techniques }\end{array}$ & $\begin{array}{l}\text { 构树 } \\
\text { Broussonetia } \\
\text { papyrifera }\end{array}$ & $\begin{array}{l}\text { 中国南部地区 } \\
\text { South of China }\end{array}$ & $\begin{array}{l}\text { 传统的以构树皮为原料的造纸技艺 } \\
\text { Traditional papermaking technology with bark } \\
\text { as raw material }\end{array}$ & $\begin{array}{l}\text { 省级非遗项目 } \\
\text { Provincial intangible } \\
\text { cultural heritage }\end{array}$ \\
\hline $\begin{array}{l}\text { 拉祜族服饰制作技 } \\
\text { 艺 } \\
\text { The technique of } \\
\text { dress making }\end{array}$ & - & $\begin{array}{l}\text { 拉祜族社区 } \\
\text { Lahu community }\end{array}$ & $\begin{array}{l}\text { 传统的服饰制作技艺，包含了拉祜族的传统 } \\
\text { 文化 } \\
\text { The traditional dress making skills including } \\
\text { the traditional culture of Lahu People }\end{array}$ & $\begin{array}{l}\text { 省级非遗项目 } \\
\text { Provincial intangible } \\
\text { cultural heritage }\end{array}$ \\
\hline $\begin{array}{l}\text { 拉祜族竹编技艺 } \\
\text { Bamboo weaving } \\
\text { techniques }\end{array}$ & $\begin{array}{l}\text { 竹类 } \\
\text { Bambusoideae }\end{array}$ & $\begin{array}{l}\text { 拉祜族社区 } \\
\text { Lahu community }\end{array}$ & $\begin{array}{l}\text { 充分利用当地丰富的竹类资源制作生产生活 } \\
\text { 用具 } \\
\text { Making full use of local bamboo resources to } \\
\text { make production and living utensils }\end{array}$ & $\begin{array}{l}\text { 省级非遗项目 } \\
\text { Provincial intangible } \\
\text { cultural heritage }\end{array}$ \\
\hline $\begin{array}{l}\text { 藏族唐卡制作技艺 } \\
\text { Technique of } \\
\text { Tibetan Thangka } \\
\text { making }\end{array}$ & - & $\begin{array}{l}\text { 藏族社区 } \\
\text { Tibetan community }\end{array}$ & $\begin{array}{l}\text { 藏族社区独具特色的绘画艺术 } \\
\text { The unique painting art of Tibetan community }\end{array}$ & $\begin{array}{l}\text { 省级非遗项目 } \\
\text { Provincial intangible } \\
\text { cultural heritage }\end{array}$ \\
\hline $\begin{array}{l}\text { 康巴藏族服饰制作 } \\
\text { 技艺 } \\
\text { Technique of dress } \\
\text { making in Kangba } \\
\text { Tibetan }\end{array}$ & - & $\begin{array}{l}\text { 康巴藏区 } \\
\text { Tibetan area of Kham }\end{array}$ & $\begin{array}{l}\text { 传统的服饰制作技艺, 是康巴藏区的典型民 } \\
\text { 族文化之一 } \\
\text { Traditional dress making technique, one of the } \\
\text { typical national cultures in the Tibetan area of } \\
\text { Kham. }\end{array}$ & $\begin{array}{l}\text { 省级非遗项目 } \\
\text { Provincial intangible } \\
\text { cultural heritage }\end{array}$ \\
\hline \multicolumn{5}{|c|}{ 与生物资源利用相关的传统文化 Traditional culture related to utilization of biological resources } \\
\hline $\begin{array}{l}\text { 芦笙舞 } \\
\text { Lusheng dance }\end{array}$ & - & $\begin{array}{l}\text { 中国西南地区 } \\
\text { Southwest of China }\end{array}$ & $\begin{array}{l}\text { 拉祜族古老的民族舞蹈, 反映了拉祜族的生 } \\
\text { 产生活和历史文化 } \\
\text { The ancient dance of Lahu People, which } \\
\text { reflect the production, life, history and culture } \\
\text { of Lahu People }\end{array}$ & $\begin{array}{l}\text { 国家级非遗项目 } \\
\text { National intangible } \\
\text { cultural heritage }\end{array}$ \\
\hline $\begin{array}{l}\text { 葫芦节 } \\
\text { Gourd Festival }\end{array}$ & $\begin{array}{l}\text { 葫芦 } \\
\text { Lagenaria } \\
\text { siceraria }\end{array}$ & $\begin{array}{l}\text { 澜沧县特有 } \\
\text { Endemic to Lancang } \\
\text { County }\end{array}$ & $\begin{array}{l}\text { 拉祜族最隆重的传统节日, 体现了葫芦崇拜 } \\
\text { 为代表的生态伦理观 } \\
\text { The most solemn traditional festival of Lahu } \\
\text { People, which show the ecological ethics } \\
\text { represented by gourd worship }\end{array}$ & $\begin{array}{l}\text { 省级非遗项目 } \\
\text { Provincial intangible } \\
\text { cultural heritage }\end{array}$ \\
\hline $\begin{array}{l}\text { 布朗族山康茶祖节 } \\
\text { Shankang Tea } \\
\text { Festival of Bulang } \\
\text { People }\end{array}$ & $\begin{array}{l}\text { 茶 } \\
\text { Camellia sinensis }\end{array}$ & $\begin{array}{l}\text { 澜沧县特有 } \\
\text { Endemic to Lancang } \\
\text { County }\end{array}$ & $\begin{array}{l}\text { 布朗族最隆重的传统节日, 以崇拜茶树和祭 } \\
\text { 祀茶神为主要内容 } \\
\text { The most solemn traditional festival of Bulang } \\
\text { People to worship tea tree and sacrifice tea God }\end{array}$ & $\begin{array}{l}\text { 省级非遗项目 } \\
\text { Provincial intangible } \\
\text { cultural heritage }\end{array}$ \\
\hline $\begin{array}{l}\text { 康定四月八转山节 } \\
\text { Turn mountain } \\
\text { festival in Kangding } \\
\text { City }\end{array}$ & - & $\begin{array}{l}\text { 康定市特有 } \\
\text { Endemic to Kangding City }\end{array}$ & $\begin{array}{l}\text { 康定藏族重要的传统节日, 体现了敬畏自然 } \\
\text { 和保护环境的理念 } \\
\text { Kangding Tibetan important traditional } \\
\text { festivals, emboding the concept of reverence for } \\
\text { nature and protection of the environment }\end{array}$ & $\begin{array}{l}\text { 国家级非遗项目 } \\
\text { National intangible } \\
\text { cultural heritage }\end{array}$ \\
\hline $\begin{array}{l}\text { 康定芫根灯会 } \\
\text { Lamp Festival in } \\
\text { Kangding City }\end{array}$ & $\begin{array}{l}\text { 芫根 } \\
\text { Brassica rapa }\end{array}$ & $\begin{array}{l}\text { 康定市特有 } \\
\text { Endemic to Kangding City }\end{array}$ & $\begin{array}{l}\text { 康定地区独特的以芫根作为灯盏材料的藏族 } \\
\text { 传统节日 } \\
\text { The unique Tibetan traditional festival in } \\
\text { Kangding area, which uses genkwa root as the } \\
\text { material of Lantern festival }\end{array}$ & $\begin{array}{l}\text { 市级非遗项目 } \\
\text { Municipal intangible } \\
\text { cultural heritage }\end{array}$ \\
\hline
\end{tabular}

\section{3 县域生物多样性相关传统知识特征分析}

(1)传统知识形成与当地气候和自然资源禀赋 高度相关。澜沧县位于我国云南省西南边陲, 是我 国拉祜族主要聚居地, 拥有复杂多样的地形及气候, 孕育着丰富的生物资源, 特别是药用植物资源。调 查发现, 澜沧县拉祜族常用的药用植物以具有清热
解毒、舒筋活络等功效的居多, 如地方社区传统上 使用土获苓(Smilax glabra)治疗湿疹、皮炎等, 食之 可强身壮骨, 这与澜沧县的山地环境与潮湿炎热的 气候密切相关。澜沧县多为山区、半山区, 土壤大 多贫㾑、肥力低, 因此一些抗旱、耐贫㾑、适应性 强的传统农作物品种被当地拉祜族等各族人民保 留和种植。如可在澜沧当地贫㾑的山地生长的优良 
地方品种 “红旱谷”, 主要是基于当地人的饮食习惯 和自然条件而被部分拉祜族村寨保留并继续种植, 异地种植后, 难以保持其优良特性。康定市地处四 川盆地西缘山地和青藏高原的过渡地带, 多为高山 峡谷区, 地形复杂多变, 垂直地带性明显, 孕育了 丰富的中、藏医药用植物资源, 如秦芜(Gentiana macrophylla)、红景天 (Sedum rosea)、川贝母 (Fritillaria cirrhosa)、羌活(Notopterygium incisum) 等。此外, 一些耐寒、耐旱、适应性强的传统农作 物品种被当地农户留种、种植。如 ‘康定青踠豆” ‘黄 燕麦, 等为当地民众的杂粮作物, 具有耐寒、耐旱的 性状特征, 是当地人们经过悠久的栽培历史选育出 的适应当地自然环境的传统品种。康巴服饰是康定 藏族同胞最显著的民族文化特征之一。康定市农区 和牧区的藏族服饰差异显著, 以适应不同的气候环 境和劳作方式。

(2)一些与地方社区日常生产生活方式密切相 关的传统知识得以保留。澜沧和康定的传统知识是 拉祜族、藏族等各族人民生产生活经验的积累, 至 今仍应用于农业生产、植物资源利用和传统文化等 方面。长期农业生产经验的积累, 形成了传统利用 农业遗传资源的知识与做法, 并以此为基础, 选育 出了优良的地方品种。如 “接骨糯”是澜沧当地各族 人民经过长期的栽培、选种而培育出的地方品种, 具有突出的食用、药用价值。当地人将其和一些草 药结合用来接骨, 也是当地节庆的必备食物原料之 一。而 '康定黑青稞, 是当地藏族人不可或缺的主食, 是地方社区经过悠久的栽培历史选育出的适应当 地高寒环境的传统品种, 口感好、营养价值较高, 也用于宗教祭祀、传统节日, 具有一定的经济文化 价值。拉祜族有着悠久的竹编历史, 把竹子和藤条 编织成各种用具, 用于日常生产生活, 这种传统的 竹编技术是拉祜族珍贵的非物质文化遗产。芦笙舞 是拉祜族生产生活形态历史流程的形象记录, 承载 着拉祜族悠久的历史文化传统, 体现出拉祜族独特 的性格特征, 是该民族现存文化传统最重要的组成 部分, 已列入国家级非物质文化遗产名录。

(3)传统文化是促进传统知识形成与发展的重 要因素。澜沧县各族人民喜食稻谷, 经过长期的栽 培和选种, 培育了“接骨糯”、“红旱谷”、“早熟稻”、“白 糯米, 等一些优良的地方品种, 用于节日和祭祀。神 山崇拜是藏族群众的主要信仰之一, 认为每座山峰
都有神灵, 不破坏生存于神山的动植物, 因而神山 及其周围形成了独特的自然保护区域, 有着丰富的 生物多样性。神水崇拜是藏族人民敬畏大自然的体 现, 形成的一系列习俗禁令有利于水生态环境的保 护。湖泊和溪水周围的森林、土石、动植物禁止采 挖和捕杀, 这在很大程度上保护了水资源及其周围 的生态环境。山神信仰是拉祜族信仰的重要组成部 分, 认为山神与村落紧密相连, 是社区的保护神 灵。拉祜族山寨周围大多有一片茂密的林地作为村 寨神灵的象征, 不允许砍伐和践踏, 从一定程度上 保护了生物多样性。拉祜族服饰的艺术图案不仅描 绘了拉祜族人民生产、生活中的场景, 还表征出拉 祜族的特点、风俗、习惯及民族迁徙的历史，具有 丰富的文化底蕴。

(4)传统知识与地方社区经济协同发展。澜沧古 茶等地理标志产品和 “澜沧栘依” (Docynia delavayi)、“康定红皮夢卜’等农产品地理标志、拉祜 族竹编和葫芦笙制作等传统技术在这方面发挥了 积极作用, 体现了传统知识的社会经济特征。康定 市建立了秦芜、川贝母、芫活和黄芪(Astragalus membranaceus) 等规范化人工种植基地, 不仅推动 了社会经济发展, 也促进了中、藏医药传统知识的 传承。一些传统文化节庆活动也在地方社区经济增 长上发挥了重要作用。如在拉祜族传统节日一一葫 芦节期间, 澜沧县举行产品交流会, 开展葫芦文化 节活动, 举行盛大的芦笙舞比赛, 不仅弘扬了拉祜 族优秀的民族文化, 增强了民族自信心与凝聚力, 更促进了民族团结, 推动了拉祜族地区经济发展。

\section{4 传统知识保护与利用策略}

\section{1 保护传承现状}

作为《生物多样性公约》和《名古屋议定书》 的缔约方, 我国在生物多样性相关传统知识保护管 理方面做出了积极的努力。国家中医药管理局、文 化和旅游部、农业农村部等有关部门对以中医药、 非物质文化遗产、地方品种资源等为重点的生物多 样性相关传统知识进行管理。澜沧拉祜族芦笙舞和 康定四月八转山节被列入国家级非物质文化遗产 名录; 拉祜族葫芦笙制作技艺、澜沧县传统手工造 纸技艺、拉祜族服饰、拉祜族竹编技艺、澜沧县葫 芦节、藏族唐卡、康巴藏族服饰、布朗族山康茶祖 节被列入省级非物质文化遗产名录, 受到《中华人 
民共和国非物质文化遗产法》保护。康定市发挥其 生态、资源、特色中藏药材的优势, 在新都桥镇建 成秦艽良种繁育基地; 在炉城镇建立川贝母良种繁 育基地; 在呷巴乡建立㒸活良种繁育基地; 在甲根 坝乡建立黄芪良种繁育基地, 保护了相关医药知识 的生物基源。截至2014年, 国家种质大叶茶树资源 圃(预海)收集保藏了 2,000 余份珍贵茶树资源材料, 其中包括了云南大叶茶种质资源。

包括习惯法、传统节庆等传统文化和包括祭 祀、神山神林等宗教方式在内的地方社区行动促进 了相关传统知识的保护与传承。本次调查发现澜 沧、康定受传统文化或宗教方式保护的传统知识分 别为19项、12项。其中 “澜沧栘依, 、葫芦节、拉祜 族春节、芦笙舞、 ‘康定芫根, 、康定芫根灯会、康 定四月八转山节等受传统节日保护; 山神崇拜、神 山崇拜、神水崇拜等受宗教信仰保护; “红旱谷”、“康 定黑青稞”、“康定黄燕麦”、青稞酒酿造工艺、稭粑 制作工艺、酥油提取工艺等受祭祀保护; 受祭祀和 传统节日双重保护的传统知识有拉祜族葫芦笙制 作技艺、糯米粑粑制作技术、米酒酿造技术、低族 水酒制作技术等。

\section{2 传统知识的利用潜力}

澜沧县、康定市政府在脱贫攻坚和产业发展中, 已广泛应用生物多样性相关传统知识、创新和做 法。澜沧县是世界茶树原产地之一, 是追溯云南大 叶种普洱茶千年茶文化的重要区域之一。种茶、制 茶、喝茶已成为当地人民日常生产生活的有机组成 部分。澜沧县景迈、竹塘、富邦、富东、惠民等地 方社区创造并积累了选育和栽培茶树的知识和有 效做法, 并用以维持布朗族、傣族等民众千百年来 赖以生存的经济来源。澜沧县聚居的村落大多种植 了高产、连片、优质的高优生态茶园。澜沧古茶品 质优异, 是国家地理标志产品, 已成为澜沧县脱贫 致富奔小康的重要经济支柱和主导产业。“澜沧栘 依, 果实可食用、药用, 并适合酿酒。当地人将成熟 的栘依果晒干入药, 治疗消化不良。“澜沧栘依”果以 其独特的口感和生态无污染的特点而广受欢迎, 已 成为当地助农增收的重要产业, 是澜沧县首个获得 国家地理标志证明商标的产品。芫根(Brassica rapa) 是藏区重要的传统蔬菜之一, 已有 1,000 多年的栽 培历史。“康定芫根”是康定市藏族同胞选育的优良 地方品种, 可作为蔬菜食用, 亦可药用, 并且在康
定市藏族社区具有重要的文化价值, 被用于藏族重 要传统节日一一燃灯节, 因此康定市的燃灯节又被 称为“芫根灯会”。康定藏族人民创造性地利用芫根 作为燃灯节的灯戔材料的传统做法, 促进了“康定 芫根, 种质资源的保存, 并形成了规模化种植, 产生 了极高的经济效益, 于2010年被批准为“农产品地 理标志”。“康定红皮萝卜’是康定县炉城镇特有地方 农产品, 是藏族同胞经过悠久的栽培历史选育出的 适应当地生态环境的传统品种。康定红皮萝卜品质 优良, 已经形成规模化和产业化, 并于2014年被批 准为“农产品地理标志”。

\section{3 保护传承与可持续利用的制约因素}

(1)传统知识保护立法仍不健全。过去10年中我 国已颁布和修订了《中医药法》《非物质文化遗产 法》《种子法》《专利法》等相关法律, 但由于缺少 与《名古屋议定书》直接对接的国家立法, 遗传资 源及相关传统知识获取与惠益分享的国家制度至 今未能建立, 这制约了传统知识的传承与发展。如 许多拉祜族和藏族医药传统知识被企业无偿使用, 损害了传统知识持有人的利益。由于传统知识持有 者和利用者之间的公平惠益分享机制未能建立, 传 统知识持有者常常不愿意与企业合作开发, 导致这 些传统知识不能公开和应用, 影响了传统知识最大 化地发挥其价值。

(2)传统知识传承受到威胁。随着社会经济的发 展, 外来文化不断引入, 对澜沧和康定地方社区传 统生活生产方式、传统文化等造成一定程度的负面 影响。部分传统地方品种因其经济效益差、产量低 而逐渐被取代甚至面临丧失的威胁, 如澜沧县“接 骨糯’、康定黑青稞”、‘康定黄燕麦’因产量低, 目前 主要为满足自家食用的需要, 未大面积种植。随着 高产新品种的推广, 这些传统地方品种的种植面积 逐渐减少, 有消失的风险。受外来饮食文化的冲击, 低族人民的传统饮食习惯逐渐发生改变, 从而导致 低族水酒酿造技术使用频率降低。

(3)传统知识保护意识薄弱。澜沧、康定等县的 地方社区居民对生物多样性相关传统知识的传承 观念淡薄, 导致传统知识的传承范围减小、传承人 缺失。本次调查记录的澜沧县和康定市生物多样性 相关传统知识, 无传承措施的约占 $89 \%$ 。目前, 青稞 酒酿造工艺等一些传统知识的传承者基本是中老 年人, 大部分年轻人对现代文化憧憬向往, 往往会 
选择学习现代生产技能或外出打工, 以获得更高的 经济收入。

(4)承载传统知识的生物资源减少。山区和自然 保护区的周边社区经济相对落后, 社区居民对野生 生物资源的依赖性较大，如康定市沙德镇、贡嘎山 乡的居民大部分收入都来自于虫草和松茸采集, 甚 至出现了一定数量专门从事商业采集的居民, 导致 对当地野生资源过度利用。本次调查中, 受过度开 发利用影响的传统知识约占38\%。此外，“康定黑青 稞”、“接骨糯”、“红旱谷”、早熟稻等一些优良地方 品种通过当地农户自家留种保存, 缺乏有效规范的 保护措施。

\section{4 传统知识保护对策建议}

(1)建立传统知识获取与惠益分享国家制度。作 为《名古屋议定书》的缔约方，我国应采取立法、 行政或政策措施，以确保使用者同持有生物多样性 相关传统知识的地方社区公正公平地分享利用此 种知识所产生的惠益。因此, 应建立健全生物多样 性相关传统知识保护、获取和惠益分享的制度和体 制, 完善专利申请中生物多样性相关传统知识来源 披露制度, 形成获取生物多样性相关传统知识的 “共同商定条件”和“事先知情同意”程序，建立生物 多样性相关传统知识获取与惠益共享的管理机制、 管理机构及技术支撑体系, 并构建相关的信息交换 机制, 对以学术研究、商业为目的的传统知识获取 进行分类管理。

(2)加强宣传教育, 提升保护传承意识。基于本 次调查获得的澜沧县、康定市生物多样性相关传统 知识的数据信息, 编写科普教育材料, 充分利用传 统媒体和新媒体, 加大力度宣传非物质文化遗产、 传统地理标志产品、民族文化生态保护区等传统知 识保护传承的成功案例, 提升全社会保护生物多样 性相关传统知识的自觉性和参与度。加强传统知识 对民族发展、文化传承、生物多样性保护与可持续 利用的重要意义的宣传, 积极动员鼓励企业和社会 组织共同参与生物多样性相关传统知识的保护与 惠益分享工作, 形成全社会共同推进生物多样性相 关传统知识保护与传承的氛围。

(3)因地制宜开展传统知识保护。民族文化生态 保护区是我国实践整体保护少数民族非物质文化 遗产的重大创新，其建设实践为国际上少数民族非 物质文化遗产的保护贡献了中国智慧。在澜沧县、
康定市非物质文化遗产资源富集的地区设立民族 文化生态保护区，对保护区内各类资源进行整体保 护，构建由当地政府、专家和社会民众及团体等组 成的多元主体参与机制, 并开展获取与惠益分享示 范。在保护传统知识的同时，基于澜沧县、康定市 社区生计实际状况，充分利用地方有关政策，发展 特色产业，促进地方社区可持续发展。

(4)推动相关生物资源的保护和可持续利用。破 除单一的经济发展模式，拓宽生计维持渠道，降低 对野生生物资源的依赖。通过建立自然保护区和药 材良种繁育基地等方式, 强化承载传统知识的生物 资源的保护，并进行传统利用的野生生物资源的人 工栽培与驯化技术的研发与推广，或借鉴民间传统 栽培经验，扩大资源量，以促进相关生物资源的可 持续利用。建立传统地方品种的原生境保护区、保 护小区，并加强种质资源的收集保藏和优异基因挖 掘，为保障我国粮食安全做出贡献。

致谢: 感谢中央民族大学朴金丽、薛达元、郡桦、 成功、刘春晖、卫萍萍、孙璐等参加实地调查并提 供数据的研究人员。

\section{ORCID}

刘冬梅 (D) https://orcid.org/0000-0001-9190-8871

李俊生 (D) https://orcid.org/0000-0002-0405-0932

杨京彪 (i) https://orcid.org/0000-0003-2476-0381

\section{参考文献}

Antons C (2010) The role of traditional knowledge and access to genetic resources in biodiversity conservation in Southeast Asia. Biodiversity and Conservation, 19, 1189-1204.

Cheng G, Wang C, Xue DY (2012) Attitude to the traditional knowledge of international governmental organizations and suggested strategies of China. Biodiversity Science, 20, 505-511. (in Chinese with English abstract) [成功, 王程, 薛达元 (2012) 国际政府间组织对传统知识议题的态度 以及中国的对策建议. 生物多样性, 20, 505-511.]

Intergovernmental Science-Policy Platform on Biodiversity and Ecosystem Services (IPBES) (2019) Summary for policymakers of the global assessment report on biodiversity and ecosystem services of the Intergovernmental SciencePolicy Platform on Biodiversity and Ecosystem Services. https://ipbes.net/sites/default/files/ipbes_7_10_add.1_en_1.p df. (accessed on 2019-09-17)

Jasmine B, Singh Y, Onial M, Mathur VB (2016) Traditional 
knowledge systems in India for biodiversity conservation. Indian Journal of Traditional Knowledge, 15, 304-312.

Jeeva S, Mishra BP, Venugopal N, Laloo RC (2006) Traditional knowledge and biodiversity conservation in the sacred groves of Meghalaya. Indian Journal of Traditional Knowledge, 5, 563-568.

Leni DC, Dixon TG, Antonio PC, Sofronio CC (2016) Indigenous knowledge and practices for the sustainable management of Ifugao forests in Cordillera, Philippines. International Journal of Biodiversity Science, Ecosystem Services \& Management, 12, 5-13.

Liu DM, Xue DY, Cai L, Li JS, Xiao NW (2018) Establishing a national indicator system in China for the assessment of traditional knowledge associated with biodiversity. Biodiversity Science, 26, 1350-1357. (in Chinese with English abstract) [刘冬梅, 薛达元, 蔡蕾, 李俊生, 肖能文 (2018) 中国生物多样性相关传统知识调查与评估指标体 系构建. 生物多样性, 26, 1350-1357.]

Pushpangadan P, George V, Ijinu TP, Chithra MA (2018) Biodiversity, bioprospecting, traditional knowledge, sustainable development and value added products: A review. Journal of Traditional Medicine \& Clinical Naturopathy, 7, 1-7.

Wang GP, Xue DY, Wen Y, Cheng G, Min QW (2019) Diversity of traditional knowledge related to utilization of biological resources by $\mathrm{Tu}$ Nationality in China. Biodiversity Science, 27, 735-742. (in Chinese with English abstract) [王国萍, 薛达元, 闻蔌, 成功, 闵庆文 (2019) 土族生物资源利用相关的传统知识多样性. 生物多样性, 27, 735-742.]
Xue DY (2019) Conservation and outlook of traditional knowledge associated with biodiversity. Biodiversity Science, 27, 705-707. (in Chinese) [薛达元 (2019) 生物多 样性相关传统知识的保护与展望. 生物多样性, 27, 705-707.]

Xue DY, Guo L (2009) On concepts and protection of traditional knowledge. Biodiversity Science, 17, 135-142. (in Chinese with English abstract) [薛达元, 郭泺 (2009) 论传统知识的概念与保护. 生物多样性, 17, 135-142.]

Yang LX, Pei SJ, Zhang Y (2019) Action research on Tibetan sacred nature sites (SNS) conservation in Tibetan community in NW Yunnan. Biodiversity Science, 27, 749-757. (in Chinese with English abstract) [杨立新, 裴盛 基, 张宇 (2019) 滇西北藏区自然圣境与传统文化驱动 下的生物多样性保护. 生物多样性, 27, 749-757.]

Yang YH, Bai KY, Jarvis D, Long CL (2019) Xishuangbanna cucumber landraces and associated traditional knowledge. Biodiversity Science, 27, 743-748. (in Chinese with English abstract) [杨云卉, 白可喻, Devra Jarvis, 龙春林 (2019) 西双版纳黄瓜农家品种及其传统知识. 生物多样性, 27, 743-748.]

Zhang YY (2019) China's strategy for incorporating traditional knowledge associated with biodiversity into international multi-lateral agreements. Biodiversity Science, 27, 708-715. (in Chinese with English abstract) [张渊媛 (2019) 生物多 样性相关传统知识的国际保护及中国应对策略. 生物多 样性, 27, 708-715.]

(责任编委：薛达元 责任编辑：黄祥忠) 